\title{
A Least Cost Long -Term Energy Supply Strategy for Sri Lanka using Petroleum, Coal and Natural Gas
}

\author{
B.M.C. Pasindu, K.T.M.U. Hemapala and K.K.W. Siriwardena
}

\begin{abstract}
Long term energy sector planning is essential for a country to achieve sustainable development in all its social, economic and environmental dimensions. Furthermore, it will ensure the energy supply security of the country. The energy supply side needs to deal with technical, economic and environmental assessments of all energy supply options such as natural resources, energy imports, energy exports etc. The energy supply side should follow policy directives of the government and should take into account all other related constraints. Similarly, the demand side too has to deal with the assessment of future energy needs of various consumption sectors, policy directives etc.

In this study the software MESSAGE was used to model the energy chains associated with petroleum, coal and Natural Gas (NG) in relation to Sri Lanka. The national energy chain was modelled considering the modernizations of the existing refinery through the introduction of NG to the energy sector and the introduction of electric vehicles. In addition, the viability of constructing a urea plant was also explored.
\end{abstract}

Keywords: Long Term Energy Planning, Energy chain modelling, Least Cost, Technical, Economical.

\section{Introduction}

Sri Lanka being a country with a scarcity of fossil fuels has to depend mainly on the imports of petroleum and coal, for its energy requirements. Although coal is used only for electricity generation, petroleum products are used for a variety of applications such as transportation, electricity generation, industrial uses etc. Furthermore at the moment, Sri Lanka does not use Natural Gas (NG) to meet its energy needs. However, potential NG fields have been found in Sri Lanka in the recent past. On the demand side, the transport sector in Sri Lanka has just begun to move towards a new era with electrical vehicles. The effects of introducing such technologies also need to be analysed ensuring maximum benefits to the country. NG can be also used as a raw material in the manufacture of urea.

Presently, a comprehensive study on future energy planning is being done only for the electricity sector of Sri Lanka which is the wellknown Long Term Generation Expansion Plan (LTGEP) prepared by the Ceylon Electricity Board (CEB) [1,2]. The LTGEP considers only the electricity sector of Sri Lanka and derives its results using the optimization software named Wein Automatic System Planning (WASP) [1,2]. The results of the LTGEP are valid only for the electricity sector. However, since petroleum, coal and NG can be used not only for electricity generation, but also for other applications such as transportation and industrial uses, the results of the LTGEP might become invalid when all those sectors are considered.

Therefore, the analysis of a model covering the energy chains associated with petroleum, coal, NG and electricity will give more accurate results pertaining to the future energy sector of Sri Lanka. The software package "Model for Energy Supply Strategy Alternatives and their General Environmental Impacts" (MESSAGE) developed by the International Atomic Energy Agency can facilitate the modelling and simulating of such a model [3].

The objective of the study was to prepare a model to formulate the least cost long-term energy supply strategy for Sri Lanka using petroleum, coal and natural gas for the period from 2016 to 2035. The paper has 7 sections including an overview about MESSAGE, preparation of the energy network for Sri Lanka, results of the study, sensitivity analysis, limitations of the model and conclusions.

Eng. B.M.C. Pasindu, AMIE(Sri Lanka), B.Sc. Eng

(Hons), M.Sc., University of Moratuwa. Presently,

Assistant Director(Regulatory Affairs), Public Utilities

Commission of Sri Lanka.

Email:bcpasindu@gmail.com

Eng. (Dr.) K.T.M.U. Hemapala, AMIE(Sri Lanka), B.Sc.

Eng. (Hons), Ph.D., Senior Lecturer, Dept. of Electrical

Engineering, University of Moratuwa.

Email:udayanga@elect.mrt.ac.lk

Eng. K.K.W. Siriwardena, AMIE(Sri Lanka), B.Sc. Eng. (Hons), M.Phil, Presently, Director, Tariff and Economic Affairs, Public Utilities Commission of Sri Lanka.

Email:kanchana@pucsl.gov.lk 


\section{Overview of MESSAGE}

The software MESSAGE can be used to model and evaluate alternative energy supply strategies under certain constraints. The modelling procedure is based on the building of energy flow networks. The energy flow networks represent the conversion of energy starting from its primary situation (or resource situation) and ending up at its final energy level. Figure 1 show a typical energy-flow network used in a MESSAGE model [5].

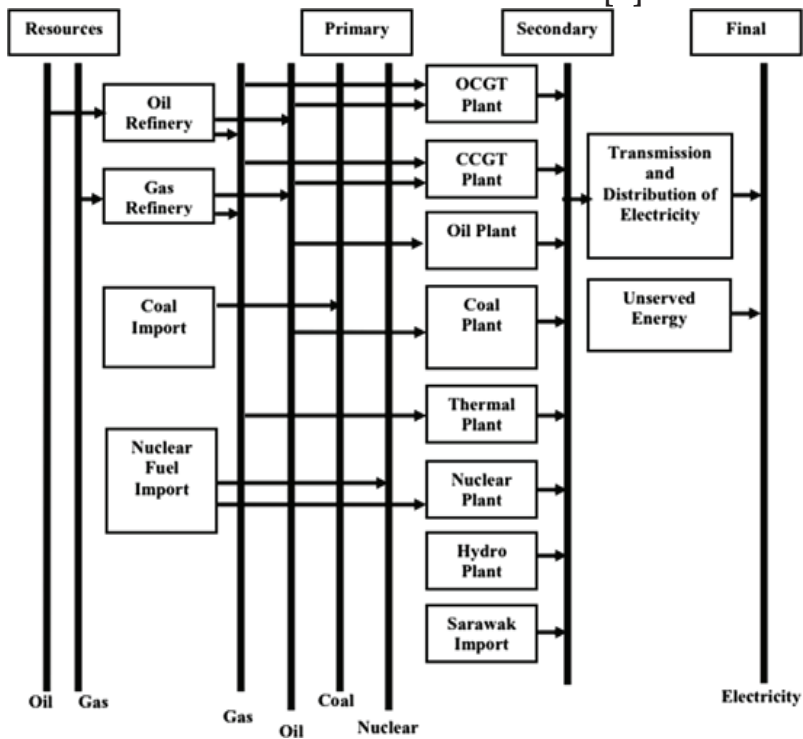

Figure 1 - A typical energy-flow network

Between the primary energy level and the final energy level, there can be several other energy levels. In Figure 1, there are four main energy levels, namely "Resources", "Primary", "Secondary" and "Final". The Final energy level represents a pre-determined energy demand, which is distributed according to the type of consumption such as heat, motor fuel, electricity etc. By using MESSAGE, the performance of a particular technology can be compared with its alternatives on a life cycle analysis basis under different national or local conditions.

Modelling an energy system using MESSAGE can accommodate items like time frame, load region, energy levels, energy forms, technologies, resources, demand and constraints.

MESSAGE allows modelling the impacts on the environment caused by the energy sector activities. Researchers have used the MESSAGE model for energy planning in their respective counties under various conditions $[6,7,8,9]$. The paper [6] examines the global impacts of a policy that internalizes the external costs (related to air pollution damage, excluding climate costs) of electricity generation using a combined energy systems and macroeconomic model. Starting point is the estimates of the monetary damage costs for $\mathrm{SO}_{2}, \mathrm{NO}$, and particulate matter per $\mathrm{kWh}$ electricity generated, taking into account the fuel type, sulphur content, removal technology, generation efficiency, and population density. However, in this study the environmental factors have not been considered.

\section{MESSAGE Model of the Sri 3.1 Energy Levels}

Three main energy levels "Primary", "Secondary" and "Final" were taken into consideration in building the energy supply network of Sri Lanka. Furthermore in this study, the electricity generation from hydro power plants and NCRE power plants has not been considered. The rationale behind this is described in Section 3.3- "Demand Forecast Electricity".

\section{Primary Energy Level}

The primary energy level contains coal, crude oil, Liquefied Natural Gas (LNG - imported), Natural Gas (NG - extracted indigenously) and nuclear fuels. Under coal, two types are considered. They are "Coal West-South" and "Coal Trinco". These two cases have been considered in LTGEP (2015-2034) too [1]. Even though the chemical composition is same in both types, the costs differ since "Coal West South" has a barging cost. Thus, the cost of "Coal West-South" is higher than that of "Coal - Trinco".

\section{Secondary Energy Level}

This includes refined petroleum products and electricity (generation). The petroleum products considered here are diesel, gasoline, fuel oil (FO 180 and FO 380 were aggregated), Avtur, Naphtha, Liquefied Petroleum Gas (LPG) and kerosene.

\section{Final Energy Level}

The components of the final energy level are Avtur, Coal (Industrial), Diesel (Household and Commercial), Diesel (Transport), Diesel (Industrial), Fuel oil (Household and Commercial), Fuel oil (Industrial), Kerosene (Household and Commercial), Kerosene (Industrial), LPG (Household and Commercial), LPG (Industrial), NG (Household and Commercial), NG (Industrial), NG (Transport), Electricity (Transport), Electricity (Distribution) and Urea. Even though urea is not a type of energy, it was included into the energy flow network by including it at the final energy 
level. The methodology of including it into the energy flow network is described in Section 3.4, Demand Forecast - Urea.

\subsection{Demand Forecast for Petroleum Products (Industrial, Transport and Household/Commercial Sector)}

MESSAGE will need demand forecasts for energy forms included at the final energy level. The demand forecast has to be specified externally depending on a suitable analysis on the demand side. The demand forecast for the industrial sector is provided in the report Initial Natural Gas Utilization Road Map [4]. It discusses two scenarios, namely NG1 and NG2 under which NG can be introduced to the industrial sector. Under NG1 scenario, a low level of penetration of NG is assumed, while a high level is assumed under NG2 scenario. In this analysis, the viability of scenario NG1 was tested with the MESSAGE model. Table 1 shows the demand forecast obtained for the industrial sector using the model.

Table 1 - Forecast demand 2014 - 2036

\begin{tabular}{|c|c|c|c|}
\hline & \multicolumn{3}{|c|}{ Fuel consumption PJ/y } \\
\hline Year & $\begin{array}{c}\text { Household } \\
\& \\
\text { Commercial }\end{array}$ & Industry & Transport \\
\hline 2014 & 17.6 & 15.1 & 113.9 \\
\hline 2016 & 19.7 & 15.8 & 128.1 \\
\hline 2018 & 22.0 & 16.6 & 144.2 \\
\hline 2020 & 24.7 & 17.4 & 162.5 \\
\hline 2022 & 27.6 & 18.4 & 183.3 \\
\hline 2024 & 31.0 & 19.4 & 206.9 \\
\hline 2026 & 34.7 & 20.6 & 233.8 \\
\hline 2028 & 39.0 & 21.8 & 264.5 \\
\hline 2030 & 43.8 & 23.2 & 299.4 \\
\hline 2032 & 49.2 & 24.8 & 339.4 \\
\hline 2034 & 55.4 & 26.5 & 385.0 \\
\hline 2036 & 62.3 & 28.4 & 437.3 \\
\hline
\end{tabular}

To analyse the viability of introducing electric vehicles, a few assumptions had to be made and fed into the model. It is assumed that in $2020,5 \%$ of the total forecasted demand from gasoline vehicles will be substituted with electric vehicles. It will gradually be increased to $35 \%$ by 2035 . In $2025,5 \%$ of the total forecasted demand from diesel vehicles will be substituted with electric vehicles. It will gradually be increased to $25 \%$ by 2035 .

The efficiency of electric vehicles is better than that of oil powered vehicles $[10,11]$. This effect has been taken into consideration in the model.
The calculated value for the ratio -"Efficiency of an electric car: Efficiency of a gasoline car" -is 3.35 and the same ratio was taken for the diesel vehicles as well.

\subsection{Demand Forecast - Electricity}

LTGEP (2015-2034) of the CEB includes a demand forecast for the electricity sector. This demand forecast had to be adjusted to suit the MESSAGE model. In this study, the electricity generation from hydro plants was not considered due to following reasons:

a. Since electricity from hydro plants is always cheaper than that from thermal plants, there is no competition for hydro plants from coal, petroleum or NG. The first option should be hydro.

b. The electricity demand forecast which should be fulfilled by thermal plants can be derived using the information given in LTGEP (2015 - 2034).

The equation given below was used to derive the electricity demand forecast that has to be fulfilled by thermal plants [1]. A reserve margin of $20 \%$ was included in the demand forecast.

$$
\mathrm{ED}_{\text {th }}(\mathrm{n})=1.2 \mathrm{ED}(\mathrm{n})-\left[\mathrm{E}_{\mathrm{H}}(\mathrm{n})+\mathrm{E}_{\mathrm{NC}}(\mathrm{n})\right.
$$

- $\quad \mathrm{ED}_{\text {th }}(\mathrm{n})=$ Electricity demand which should be fulfilled by thermal plants in the year $n$

- $\quad E_{D}(n)=$ Electricity demand forecast for the year $n$

- $\mathrm{E}_{\mathrm{H}}(\mathrm{n})=$ Expected electricity generation from hydro plants in the year $n$

- $\mathrm{E}_{\mathrm{NC}}(\mathrm{n})=$ Expected electricity generation from Non-Conventional Renewable Energy (NCRE) plants in the year $n$

$\operatorname{ED}(n), E_{H}(n)$ and $E_{N C}(n)$ are available in LTGEP (2015 - 2034) for all the years indicated within the plan.

\subsection{Demand Forecast - Urea}

NG can be used to produce urea. Furthermore, the report -"Initial Natural Gas Utilization Road Map [4]" - discusses the building of urea plants to cater to the future urea demand. The demand forecast and other details related to the NG1 scenario were taken into consideration in this study.

The report -"Initial Natural Gas Utilization Road Map [4]" - discusses the manufacture of Ammonium Sulphate and Dimethyl Ether using NG and it gives demand forecasts for them too. However, they were not taken into consideration in this analysis since their amounts in the demand forecast are very small compared to that of urea. 
The MESSAGE model deals with energy flow networks. Therefore it does not directly support the building of a network in which NG will be used for the manufacture of urea. To mitigate this mismatch, an NG equivalent for urea was taken into consideration. Using the Net Calorific Value of NG, an equivalent for NG is derived as follows:

$1 \times 10^{15} \mathrm{~J} / \mathrm{yr}=2.6 \mathrm{Mcf} /$ day.

\subsection{Technologies}

Technologies are used for connecting two energy levels to bring about either a conversion of the energy form (e.g. producing electricity from gas) or just transforming or distributing it [9]. To be consistent with the LTGEP (20152034) of CEB, 1 USD was taken as equal to 131.55 LKR in all the calculations.

The MESSAGE model prepared in this study includes both existing and future technologies. Each technology is defined by using activity and capacity variables.

a. Activity: Activity specifies input and output energy, efficiency, variable O\&M cost and the user imposed limits on the activity.

b. Capacity: Capacity describes the installed capacity, investment cost, fixed O\&M cost, plant factor, construction period, economic life time, investment cost etc.

Furthermore, MESSAGE allows the user to define more than one activity of a technology for an alternative mode of operation. The user can impose limits or bounds on technology such as the maximum capacity that can be built on a technology, or maximum and minimum levels of output from a technology. [12]

The list of technologies modelled in MESSAGE is given below.

a. Existing Refinery: Technical and financial details related to the existing refinery were taken from the refinery office of Ceylon Petroleum Cooperation (CPC).

b. Sapugaskanda Oil Refinery Expansion and Modernization (SOREM): Technical and financial details related to the existing refinery were taken from the refinery office of CPC.

c. Existing Thermal Power Plants: Technical and financial details are provided in the LTGEP of CEB.

d. Candidate Power Plants: Technical and financial details are available in the LTGEP of CEB.

e. Urea Plant: A typical urea plant with an output capacity of 500,000t/yr was considered (details were taken from the Initial Natural Gas Utilization Road Map).

f. NG Distribution Network: Details were taken from the Initial Natural Gas Utilization Road Map.

\subsection{Cost of Fuels}

a. Crude Oil: Raw crude oil prices were obtained from the information available at the refinery office of CPC.

b. Coal: Prices of coal can be directly found from the LTGEP (2015 - 2034) of CEB.[1]

c. Gasoline, Kerosene, Avtur, Fuel oil, LPG and Diesel: Details were found in Sri Lanka Energy Balance - 2014. The import price for Avtur could not be found in any of the references. Therefore, the cost of Avtur was taken as equal to the cost of kerosene.[13,14,15]

d. Naphtha, LNG and Nuclear Energy: Prices of Naphtha, LNG and nuclear energy are available in the information obtained from Public Utilities Commission of Sri Lanka (PUCSL) (The values used by CEB in preparing WASP model for LTGEP).[1]

e. Indigenous NG: Details were taken from the report Initial Natural Gas Utilization Road Map [4]

\subsection{Energy Flows Networks}

Energy flow networks modelled in this research are given in Figure 2, Figure 3, Figure 4, Figure 5 and Figure 6.

- Figure 2 shows the network for NG. NG can be either imported or locally manufactured. NG can be used to manufacture urea in addition to its use in energy related applications.

- Figure 3 elaborates the network related to nuclear energy. The only possible usage of it is to generate electricity.

- Figure 4 shows the supply side of the petroleum. Either crude oil or refined petroleum products can be imported. Furthermore, the existing refinery or proposed SOREM can be used for refining crude oil.

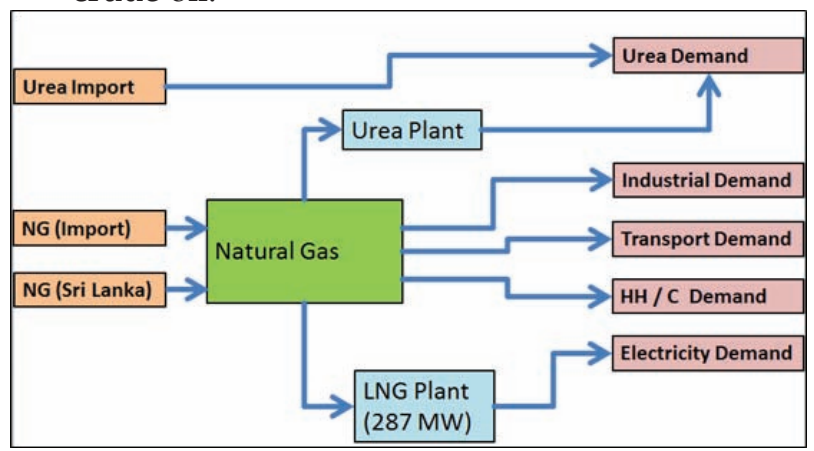

Figure 2 - Energy Flow - NG 


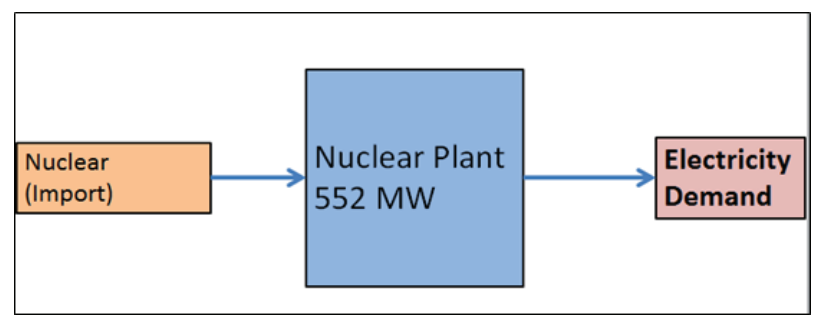

Figure 3 - Energy Flow - Nuclear

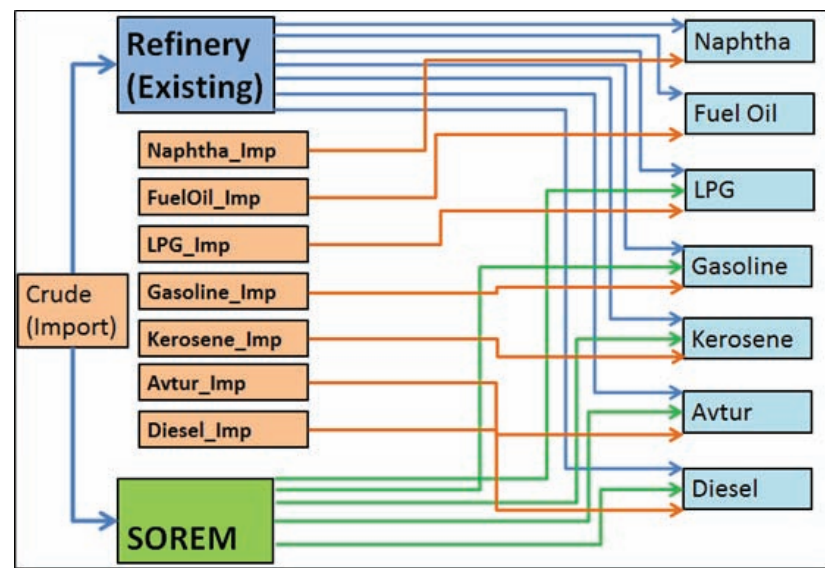

Figure 4 - Energy Flow - Petroleum Oil

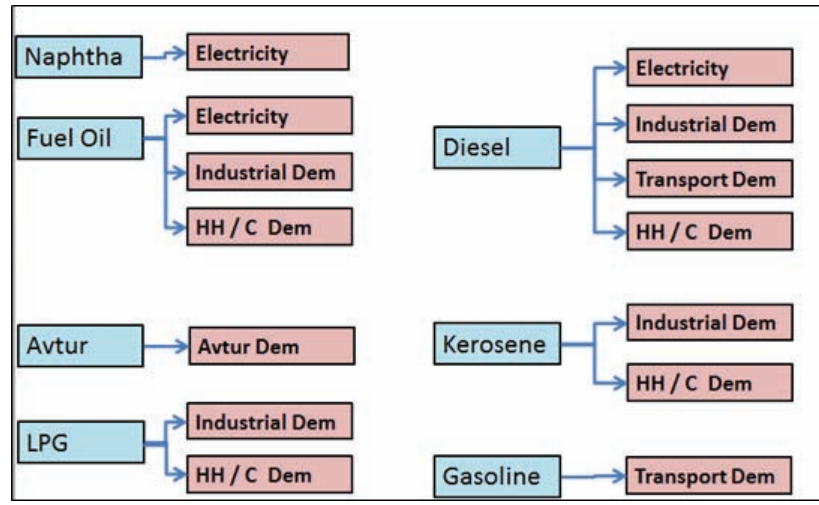

Figure 5 - Energy Flow - Uses of Petroleum

- Figure 5 elaborates the uses of petroleum products. Electricity demand, industrial demand, transport demand, household and commercial demand and demand of Avtur were considered under this study.

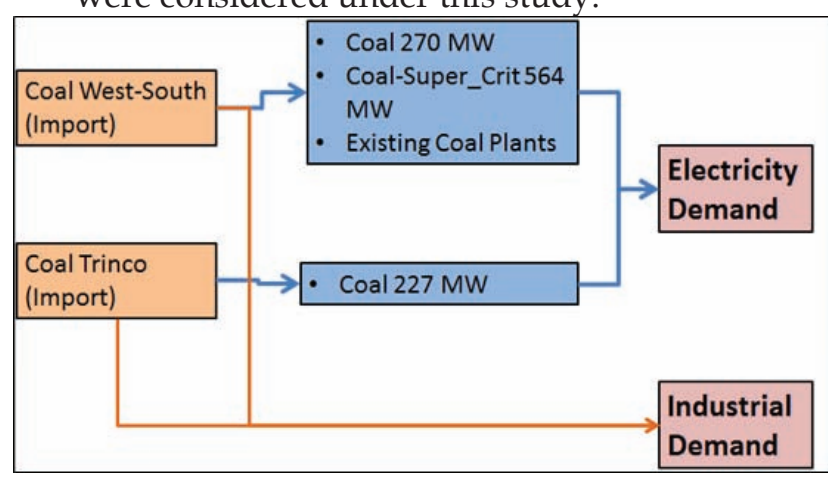

Figure 6 - Energy Flow - Coal

- Figure 6 shows the network of coal. Apart from the demand it has for electricity generation, it has a small industrial demand too .

\section{Results (Base Case) and Discussion}

MESSAGE model provides the least cost plan to fulfil the forecasted energy demand with available fuel sources. However, it does not provide the cost of the plan in Net Present Value (NPV). Therefore, to quantify the total cost of the plan, NPV of the output of the model was calculated using the software package MSExcel. For the base case, a discount rate of $10 \%$ was assumed. NPV of the solution $=61,274$ USD Millions.

\section{Fuel Imports}

Figure 7 shows the MESSAGE output on fuel imports.

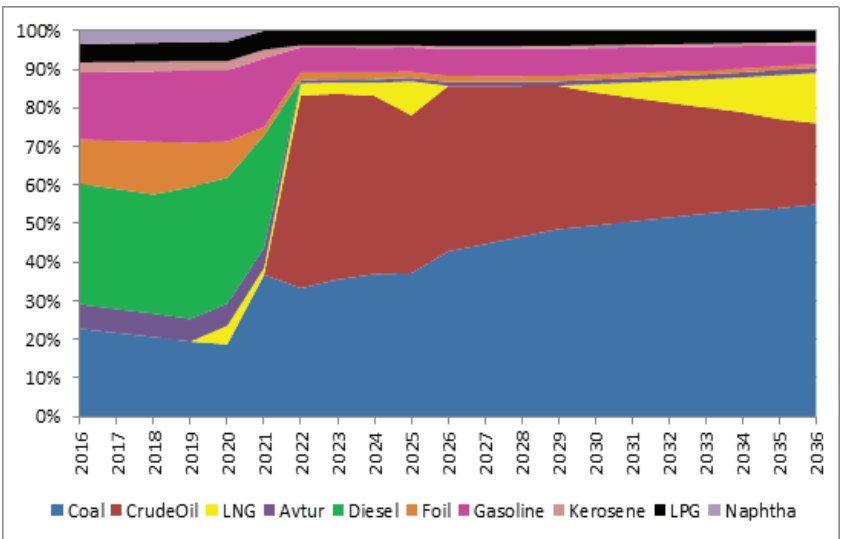

Figure 7 - Fuel Imports (Percentages)

2. Petroleum Sector

- Refined petroleum products have to be imported until 2021. Once the SOREM comes into the picture in 2022, it will be better to import crude oil and refine them in the modernized refinery, SOREM.

- The existing refinery is not considered as viable to refine petroleum products. The model does not recommend importing crude oil before the SOREM is in place. The model suggests importing refined products directly, until 2021 rather than using the existing refinery.

- The total gasoline demand of the country will be partly fulfilled by the production of SOREM. The remaining requirement of gasoline has to be imported directly.

- The total LPG demand of the country will not be fully met by the production of SOREM. The rest of the LPG demand should be imported directly.

- However, almost the entire diesel demand of the country can be fulfilled through SOREM 
output after 2022. (Diesel is the predominant output of SOREM)

3. Electricity Generation

Table 2 and Figure 8 depict the suggested nature of proposed least cost plan for electricity generation in MWyr (1MWyr = $0.11 \mathrm{GWh})$ as per the output of the model (excluding existing power plants and their retirements). It should be noted that a considerable amount of the future electricity generation accounts for the transport sector as well.

Table 2 - Electricity generation from new plants

\begin{tabular}{|l|c|c|}
\hline Year & Coal Plants (227 MW) & LNG Plants (287 MW) \\
\hline 2016 & - & - \\
\hline 2017 & - & - \\
\hline 2018 & - & - \\
\hline 2019 & - & - \\
\hline 2020 & - & 241 \\
\hline 2021 & 759 & 95 \\
\hline 2022 & 763 & 191 \\
\hline 2023 & 953 & 126 \\
\hline 2024 & 1,115 & 95 \\
\hline 2025 & 1,321 & 95 \\
\hline 2026 & 1,517 & 95 \\
\hline 2027 & 1,715 & 95 \\
\hline 2028 & 1,931 & 95 \\
\hline 2029 & 2,155 & 95 \\
\hline 2030 & 2,399 & 95 \\
\hline 2031 & 2,666 & 95 \\
\hline 2032 & 2,936 & 95 \\
\hline 2033 & 3,225 & 95 \\
\hline 2034 & 3,526 & 95 \\
\hline 2035 & 3,838 & 95 \\
\hline
\end{tabular}

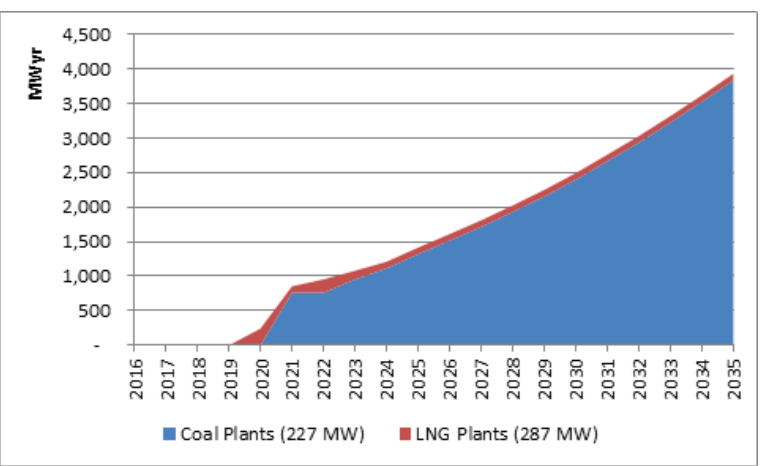

Figure 8 - Electricity generation from new plants

- The future electricity sector will be dominated by coal. This result is compatible with what is stated in the LTGEP of CEB. However, the MESSAGE model proposes LNG as a viable option for electricity generation, even though its contribution is very low. LTGEP only considers the electricity sector and it does not take into consideration the uses of LNG other than its use in electricity generation. When all the uses of LNG are considered, LNG becomes a viable option for electricity generation. Furthermore, this model considers the indigenous NG of Sri Lanka whereas the LTGEP of CEB does not consider it. None of the references mentioned above ([1] and [4]) contains a comprehensive modelling of the Sri Lanka's energy sector. Therefore, the results of this model are much more accurate than those of [1] and [4], because this model covers a vast area of the energy sector of Sri Lanka than [1] and [4].

- Use of electricity in the transport sector has become a viable option according to the output of the model. However it increases the electricity demand of the country by a considerable margin (Table 3 and Figure 9).

Table 3 - Future usages of electricity

\begin{tabular}{|l|c|c|}
\hline Year & Distribution (MWyr) & Transport sector (MWyr) \\
\hline 2016 & 1843 & 0 \\
\hline 2017 & 1968 & 0 \\
\hline 2018 & 2102 & 0 \\
\hline 2019 & 2246 & 0 \\
\hline 2020 & 2399 & 102 \\
\hline 2021 & 2517 & 155 \\
\hline 2022 & 2642 & 215 \\
\hline 2023 & 2772 & 286 \\
\hline 2024 & 2910 & 364 \\
\hline 2025 & 3055 & 653 \\
\hline 2026 & 3208 & 847 \\
\hline 2027 & 3370 & 1067 \\
\hline 2028 & 3538 & 1306 \\
\hline 2029 & 3712 & 1580 \\
\hline 2030 & 3892 & 1875 \\
\hline 2031 & 4076 & 2211 \\
\hline 2032 & 4265 & 2572 \\
\hline 2033 & 4461 & 2984 \\
\hline 2034 & 4665 & 3425 \\
\hline 2035 & 4878 & 3930 \\
\hline
\end{tabular}

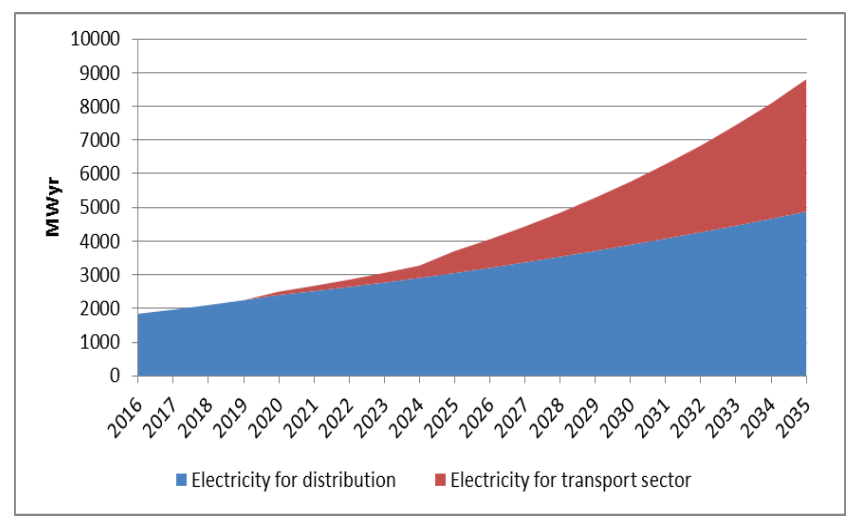

Figure 9 - Future usages of electricity 


\section{NG Sector}

It is viable to use NG in the industrial sector, transport sector, household and commercial sector, for electricity generation and as a feedstock to the urea plant.

Table 4 - NG sector (imports and indigenous)

\begin{tabular}{|c|c|c|}
\hline Year & $\begin{array}{c}\text { LNG (Imported) } \\
(\text { MWyr) }\end{array}$ & $\begin{array}{c}\text { NG (Sri Lanka) } \\
\text { (MWyr) }\end{array}$ \\
\hline 2016 & - & - \\
\hline 2017 & - & - \\
\hline 2018 & - & - \\
\hline 2019 & - & - \\
\hline 2020 & 503 & - \\
\hline 2021 & 198 & - \\
\hline 2022 & 399 & - \\
\hline 2023 & 398 & - \\
\hline 2024 & 484 & - \\
\hline 2025 & 1,420 & 1,636 \\
\hline 2026 & - & 1,878 \\
\hline 2027 & - & 2,144 \\
\hline 2028 & - & 2,444 \\
\hline 2029 & - & 2,562 \\
\hline 2030 & 407 & 2,562 \\
\hline 2031 & 777 & 2,562 \\
\hline 2032 & 1,186 & 2,562 \\
\hline 2033 & 1,638 & 2,562 \\
\hline 2034 & 2,140 & 2,562 \\
\hline 2035 & 2,888 & 2,562 \\
\hline 2036 & 3,498 & \\
\hline
\end{tabular}

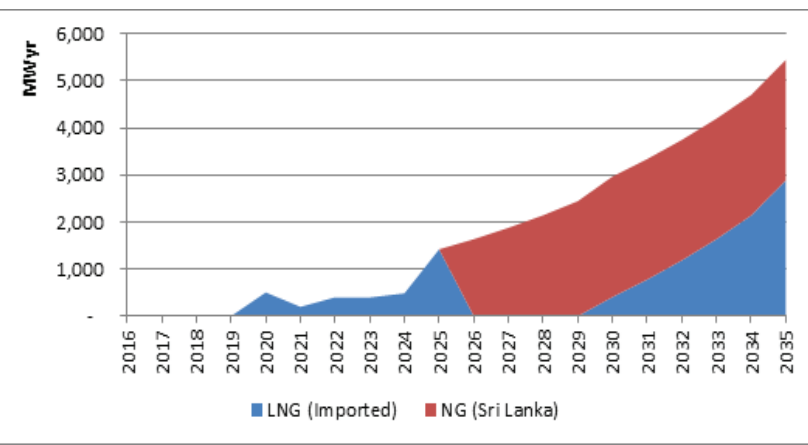

Figure 10 - NG sector (imports and indigenous)

- Even though NG is expected to be available in Sri Lanka from 2022 onwards, this model suggests that it is economical to use them from 2026 onwards. Until 2026, LNG has to be imported to fulfil the energy needs related to NG.

- After 2030, the total requirement of NG will be fulfilled partly by NG from Sri Lanka and the rest by imported LNG.

- Furthermore, the use of NG to manufacture urea is indicated as a viable option by the model, rather than importing urea directly. Urea plants thus should be built accordingly (by 2025) to fulfil the urea requirement.
5. Future Fuel Mix

Table 5 and Figure 11 describe the output of the model in relation to future fuel/energy source mix. The contribution from Hydro and NCRE to electricity generation was taken from [1]. NG includes both imports (LNG) and NG (Sri Lanka).

Table 5 - Future fuel/energy source mix

\begin{tabular}{|c|c|c|c|c|c|}
\hline & \multicolumn{5}{|c|}{ In MWyrs } \\
\hline Year & $\begin{array}{c}\text { Refined } \\
\text { Petroleum }\end{array}$ & $\begin{array}{c}\text { Crude } \\
\text { Oil }\end{array}$ & Coal & NG & $\begin{array}{c}\text { Hydro } \\
\text { and } \\
\text { NCRE }\end{array}$ \\
\hline 2016 & 6,655 & - & 1,964 & - & 748 \\
\hline 2017 & 7,109 & - & 1,968 & - & 819 \\
\hline 2018 & 7,590 & - & 1,976 & - & 889 \\
\hline 2019 & 8,175 & - & 1,977 & - & 925 \\
\hline 2020 & 8,075 & - & 1,982 & 503 & 1,007 \\
\hline 2021 & 7,176 & - & 4,288 & 198 & 1,042 \\
\hline 2022 & 1,765 & 6,454 & 4,304 & 399 & 1,083 \\
\hline 2023 & 1,845 & 6,618 & 4,887 & 398 & 1,111 \\
\hline 2024 & 1,969 & 6,733 & 5,381 & 484 & 1,141 \\
\hline 2025 & 2,114 & 6,607 & 6,012 & 652 & 1,167 \\
\hline 2026 & 2,210 & 6,623 & 6,612 & 868 & 1,181 \\
\hline 2027 & 2,315 & 6,611 & 7,218 & 1,110 & 1,211 \\
\hline 2028 & 2,410 & 6,595 & 7,880 & 1,376 & 1,234 \\
\hline 2029 & 2,509 & 6,550 & 8,565 & 1,676 & 1,266 \\
\hline 2030 & 2,596 & 6,500 & 9,311 & 2,008 & 1,290 \\
\hline 2031 & 2,685 & 6,415 & 10,129 & 2,378 & 1,308 \\
\hline 2032 & 2,760 & 6,325 & 10,954 & 2,787 & 1,334 \\
\hline 2033 & 2,830 & 6,192 & 11,838 & 3,239 & 1,364 \\
\hline 2034 & 2,882 & 6,054 & 12,760 & 3,741 & 1,398 \\
\hline 2035 & 2,923 & 5,865 & 13,714 & 4,297 & 1,451 \\
\hline
\end{tabular}

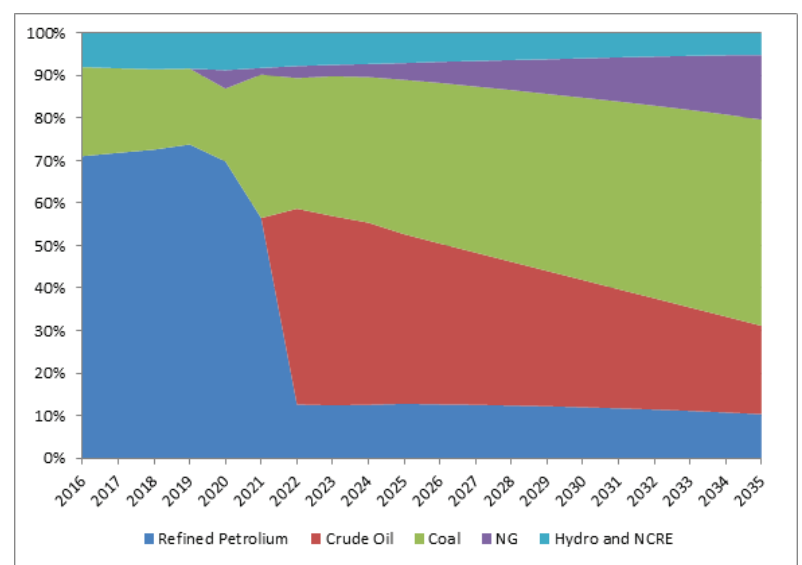

Figure 11 - Future fuel/energy source mix

6. Transport Sector - Energy Share by Fuel With the introduction of electricity to the transport sector, the future energy share will be different from what it is at present. Table 6 and Figure 12 describe the energy share by fuel in the transport sector. 
Table 6 - Energy share by fuel (transport)

\begin{tabular}{|c|c|c|c|c|}
\hline & \multicolumn{4}{|c|}{ In MWyrs } \\
\hline Year & Diesel & Gasoline & Electricity & NG \\
\hline 2016 & 2,572 & 1,490 & - & - \\
\hline 2017 & 2,700 & 1,617 & - & - \\
\hline 2018 & 2,829 & 1,744 & - & - \\
\hline 2019 & 2,970 & 1,893 & - & - \\
\hline 2020 & 3,111 & 1,940 & 102 & - \\
\hline 2021 & 3,265 & 2,063 & 155 & - \\
\hline 2022 & 3,418 & 2,179 & 215 & - \\
\hline 2023 & 3,509 & 2,256 & 286 & 124 \\
\hline 2024 & 3,607 & 2,326 & 364 & 263 \\
\hline 2025 & 3,503 & 2,398 & 653 & 419 \\
\hline 2026 & 3,512 & 2,462 & 847 & 593 \\
\hline 2027 & 3,506 & 2,524 & 1,067 & 790 \\
\hline 2028 & 3,497 & 2,575 & 1,306 & 1,005 \\
\hline 2029 & 3,472 & 2,622 & 1,580 & 1,249 \\
\hline 2030 & 3,445 & 2,655 & 1,875 & 1,519 \\
\hline 2031 & 3,398 & 2,680 & 2,211 & 1,820 \\
\hline 2032 & 3,348 & 2,689 & 2,572 & 2,153 \\
\hline 2033 & 3,274 & 2,680 & 2,984 & 2,521 \\
\hline 2034 & 3,198 & 2,655 & 3,425 & 2,930 \\
\hline 2035 & 3,094 & 2,604 & 3,930 & 3,383 \\
\hline
\end{tabular}

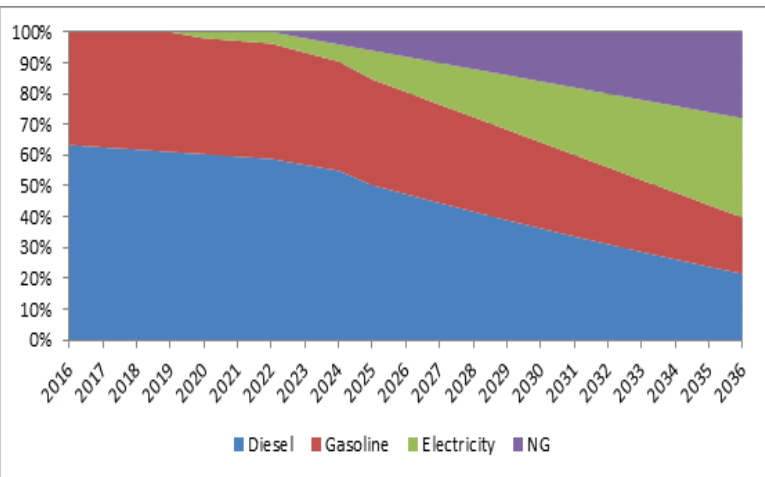

Figure 12 - Energy share by fuel (transport)

7. Industrial Sector - Energy Share by Fuel Table 7 and Figure 13 show the fuel-wise energy picture for the industrial sector as proposed by the model.

Table 7 - Energy share by fuel (industrial)

\begin{tabular}{|c|c|c|c|c|c|c|}
\hline & \multicolumn{7}{|c|}{ In MWyrs } \\
\hline Year & Coal & Diesel & Foil & Kerosene & LPG & NG \\
\hline 2016 & 108 & 98 & 203 & 40 & 51 & - \\
\hline 2017 & 112 & 99 & 204 & 42 & 54 & - \\
\hline 2018 & 119 & 100 & 205 & 45 & 57 & - \\
\hline 2019 & 121 & 101 & 206 & 48 & 61 & - \\
\hline 2020 & 126 & 101 & 207 & 51 & 65 & - \\
\hline 2021 & 131 & 102 & 208 & 55 & 69 & - \\
\hline 2022 & 136 & 103 & 209 & 59 & 73 & - \\
\hline 2023 & 142 & 102 & 204 & 61 & 76 & 11 \\
\hline 2024 & 147 & 100 & 200 & 64 & 78 & 23 \\
\hline 2025 & 153 & 98 & 195 & 66 & 81 & 36 \\
\hline 2026 & 159 & 96 & 191 & 68 & 84 & 49 \\
\hline 2027 & 166 & 95 & 186 & 71 & 87 & 62 \\
\hline 2028 & 172 & 93 & 182 & 74 & 90 & 76 \\
\hline 2029 & 179 & 91 & 177 & 77 & 93 & 91 \\
\hline 2030 & 186 & 89 & 173 & 80 & 95 & 107 \\
\hline 2031 & 194 & 87 & 168 & 82 & 98 & 123 \\
\hline 2032 & 201 & 85 & 164 & 85 & 101 & 140 \\
\hline 2033 & 210 & 83 & 160 & 88 & 104 & 159 \\
\hline 2034 & 218 & 82 & 156 & 91 & 107 & 178 \\
\hline 2035 & 227 & 80 & 151 & 94 & 111 & 198 \\
\hline
\end{tabular}

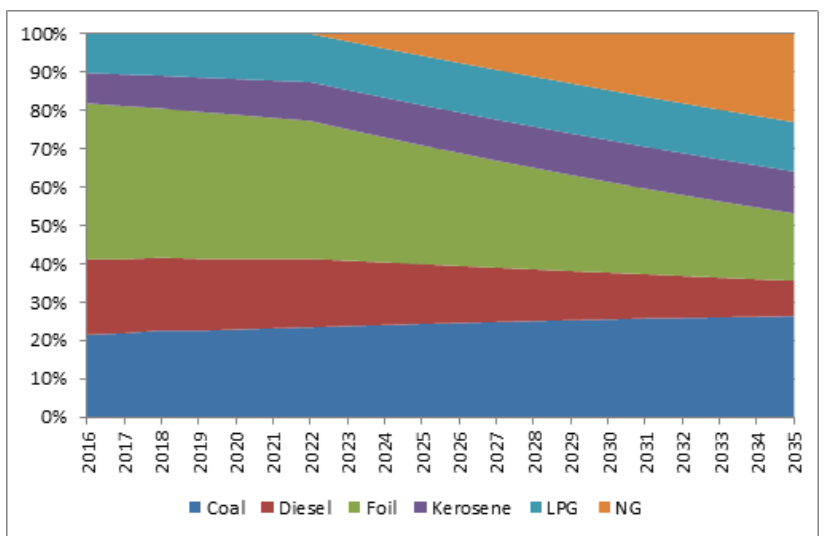

Figure 13 - Energy share by fuel (industrial)

8. Household and Commercial Sector Energy Share by Fuel

Table 8 and Figure 14 represent the fuel-wise energy picture for the household and commercial sectors as proposed by the model. The electricity consumption of household and commercial sectors has been excluded in this section.

Table 8 - Energy share by fuel (Household and Commercial)

\begin{tabular}{|c|c|c|c|c|c|}
\hline & \multicolumn{5}{|c|}{ In MWyrs } \\
\hline Year & Diesel & FOil & Kerosene & LPG & NG \\
\hline 2016 & 21 & 43 & 189 & 357 & - \\
\hline 2017 & 22 & 45 & 192 & 383 & - \\
\hline 2018 & 23 & 47 & 196 & 409 & - \\
\hline 2019 & 24 & 49 & 200 & 439 & - \\
\hline 2020 & 25 & 51 & 204 & 469 & - \\
\hline 2021 & 27 & 53 & 208 & 503 & - \\
\hline 2022 & 28 & 55 & 212 & 537 & - \\
\hline 2023 & 29 & 57 & 217 & 575 & - \\
\hline 2024 & 31 & 59 & 221 & 614 & - \\
\hline 2025 & 32 & 62 & 226 & 659 & - \\
\hline 2026 & 34 & 64 & 230 & 675 & 28 \\
\hline 2027 & 36 & 67 & 235 & 692 & 60 \\
\hline 2028 & 37 & 69 & 239 & 708 & 97 \\
\hline 2029 & 39 & 72 & 244 & 724 & 138 \\
\hline 2030 & 41 & 75 & 249 & 737 & 184 \\
\hline 2031 & 43 & 78 & 254 & 750 & 237 \\
\hline 2032 & 45 & 81 & 259 & 760 & 296 \\
\hline 2033 & 48 & 85 & 264 & 768 & 361 \\
\hline 2034 & 50 & 88 & 270 & 773 & 435 \\
\hline 2035 & 53 & 91 & 275 & 776 & 517 \\
\hline
\end{tabular}

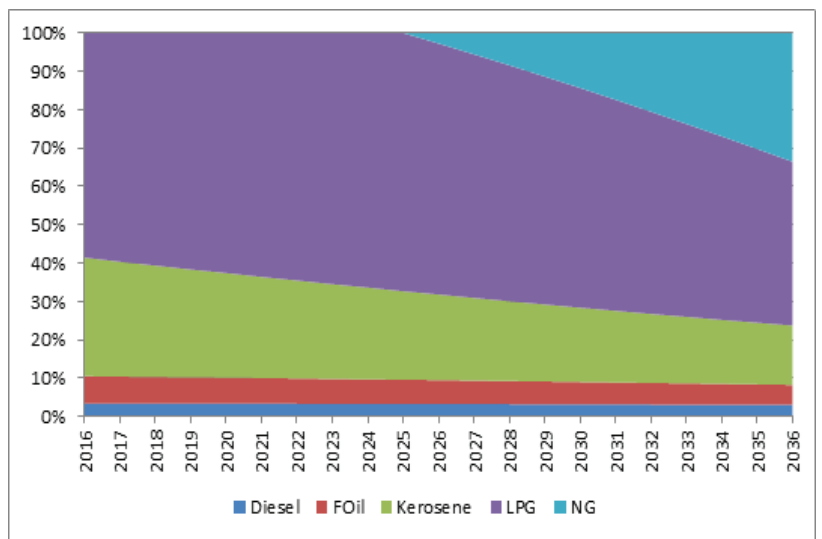

Figure 14 - Energy share by fuel (Household and Commercial) 


\section{Sensitivity Analysis}

A sensitivity analysis was done to examine the changes in the output of the base case under different scenarios. Under this part, 9 different cases were considered. This section describes the results of the sensitivity analysis. Respective NPVs for each case were calculated using MS Excel, by referring to the output of the MESSAGE model.

\section{High Discount Rate Case}

In this case, the discount rate was taken as $15 \%$. All the other parameters were kept unchanged with respect to the base case. (NPV of the solution $=43,297$ USD Millions)

- The Output of the MESSAGE model related to this case did not show any major change compared to the results of the base case.

\section{Low Discount Rate Case}

In this case, the discount rate was taken as $3 \%$. All the other parameters were kept unchanged with respect to the base case. (NPV of the solution $=114,013$ USD Millions)

- The output of the base case suggested keeping a small share for NG in electricity generation. In this scenario, NG is not suggested as a viable option to be used for the generation of electricity.

- Apart from that, there is no major change compared to the results of the base case.

\section{High LNG and NG Price Case}

In this case, the prices of imported and indigenous NG were taken to be $50 \%$ higher compared to base case values. All the other parameters (including urea price for direct imports) were kept unchanged with respect to the base case. The price of imported LNG was taken as $614.14 \mathrm{USD} / \mathrm{kWyr}$ and the price of indigenous NG was taken as 447.95 USD $/ \mathrm{kWyr}$. (NPV of the solution $=62,390 \mathrm{USD}$ Millions)

- In this case, the model output suggests delaying the construction of urea plants by one year. In the base case, the first urea plant will come in 2025, although in this case it will get delayed up to 2026 .

- The total number of urea plants by 2035 in the base case was 3 . In this case, it is only 2 . Therefore, a part of the country's urea demand has to be fulfilled by importing urea.

- The output of the base case suggested keeping a small share for NG in electricity generation from future power plants. In this scenario, NG is not suggested as a viable option to be used in the generation of electricity. The model selects coal as the alternative.

- The proposed result of the industrial sector under this case differs from that under the base case. The share of the NG has decreased with respect to that of the base case.

\section{Low LNG and NG Prices}

In this case, the prices of imported and indigenous NG were considered as 50\% lower compared to base case values. All the other parameters (including urea price for direct imports) were kept unchanged with respect to the base case. The price of imported LNG was taken as 204.71 $\mathrm{USD} / \mathrm{kWyr}$ and the price of indigenous NG taken as $149.32 \mathrm{USD} / \mathrm{kWyr}$. (NPV of the solution $=59,589$ USD Millions)

- The share taken by NG in the electricity generation has increased and that of coal has decreased (from future power plants).

\section{High Coal Price Case}

In this case, the price of coal was considered as $50 \%$ higher compared to the base case value. All the other parameters were kept unchanged with respect to the base case. The price of coal (West South) was taken as 173.02 USD/kWyr and the price of coal (Trinco) was taken as 167.89 USD/kWyr. (NPV of the solution = 63,561 USD Millions)

- There was no major change compared to the results of the base case.

\section{Low Coal Price Case}

In this case, the price of coal was taken to be $50 \%$ lower when compared to the base case value. All the other parameters were kept unchanged with respect to the base case. The price of Coal (West South) was taken as 61.09 USD/kWyr and the price of Coal (Trinco) was taken as $55.96 \mathrm{USD} / \mathrm{kWyr}$. (NPV of the solution $=58,875$ USD Millions)

- The output of the base case suggested keeping a small share for NG in the electricity generation of future power plants. In this scenario, NG is not suggested as a viable option to be used in the generation of electricity. The model selects coal as the alternative.

\section{High Petroleum Price Case}

In this case, the prices of all the petroleum products and crude oil were taken to be $50 \%$ higher when compared to the base case value. (NPV of the solution $=85,180$ USD Millions)

- There was no major change compared to the results of the base case 


\section{Low Petroleum Price Case}

In this case, the prices of all the petroleum products and crude oil were taken to be $50 \%$ lower when compared to the base case value. (NPV of the solution $=37,048$ USD Millions)

- Under this case, SOREM becomes nonviable. The model suggests as the optimal solution, the import of all the petroleum products.

- NG is not suggested as a viable option to be used in the generation of electricity. The model selects coal as the alternative.

9. Case of Abandoning New Coal Power Plants (NPV $=64,181$ USD Millions )

If no new coal power plants are allowed in the future, the next economical option will be NG (both local NG and imported LNG). Figure 15 shows the import of fuel under this case throughout the period considered in the planning.

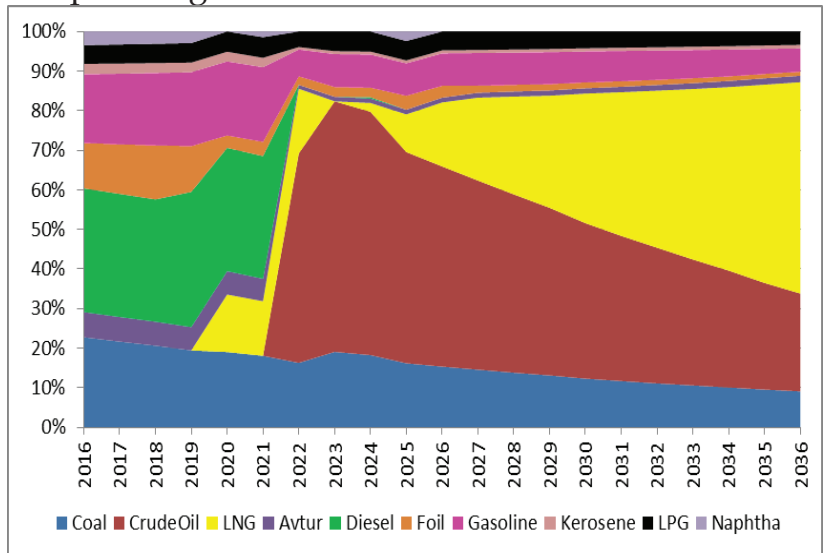

Figure 15 - Imports (No new Coal Plants)

However, coal has to be imported in future to feed the existing coal power plants and to fulfill the expected industrial demand.

\section{Limitations of the Model}

The model prepared in this study using MESSAGE has some limitations. It does not provide the following information with respect to the electricity sector.

a. Information related to hydro plants: Since electricity generation from hydro plants is cheaper than that from coal, petroleum or NG, it was not taken into consideration. Demand forecasts fed into the model consider only the electricity demand that should be met by thermal power plants.

b. Furthermore, this model does not take variables such as Peak Demand, LOLP, Rainfall etc., into consideration.

Therefore, the results of this model in relation to the electricity sector should be fine-tuned through a separate electricity planning exercise such as LTGEP of CEB. Also, this model does not consider the seasonal variations of energy demand. However, since this is a long term plan, the precise details on seasonal variations of energy demand throughout a year are not that important. Furthermore, the model prepared in this study does not include the effects of environmental costs. This limitation occurred due to the unavailability of environment-specific input data to feed into the model. With the inclusion of these environmental effects in the model, it will give an optimal plan rather than a least-cost plan.

\section{Conclusions}

1. Petroleum Sector

The main component related to the petroleum sector is the refinery. As stated in the results of the study and in the sensitivity analysis, it is clear that the most economical option is to implement the SOREM project. In the sensitivity analysis, SOREM becomes nonviable only in the "Low Petroleum Price (50\% Low)" case. In all the other scenarios, SOREM becomes viable.

This suggests that the least cost option should include the implementation of the SOREM project. However, expansions and modernizations of the existing refinery will take about five years. Therefore, the earliest possible year of having the upgraded refinery will be 2022. For the period from 2016 to 2021, the output of the model suggests to import refined petroleum products directly, rather than using the existing refinery. It proposes that the use of the existing refinery in the least cost energy plan cannot be justified. Therefore,

- The existing refinery should be upgraded to SOREM (First year of operation = 2022) and

- If the upgrading of the refinery (SOREM) is not possible, it will be more economical to import petroleum products rather than using the existing refinery.

\section{Electricity Sector}

As discussed in the results, the MESSAGE model suggests coal as the best option for electricity generation. Two types of coal plants were fed into the model and the model selected the 227 MW coal plant (which uses Coal Trinco) over 275 MW coal plant (which uses Coal - West South). There is a small contribution from NG plants to fulfil electricity demand. However, the model does not select any new power plant run by diesel, naphtha or fuel oil. Also it does not select nuclear power plants.

Coal is the most economical option for electricity generation in the planning horizon. 


\section{Phasing in of NG/LNG}

According to the output of the model, using NG for transport/industrial/household and commercial sectors will be economically viable. The plans fed into the model, as least the cost options, were accepted by the model. Therefore policies should be prepared and decisions taken targeting the introduction of NG to the energy sector. Even in the sensitivity analysis done for the high NG/LNG price case, NG became viable for the transport sector and the household and commercial sector in the given plans. There is a slight reduction in the future NG usage for industrial sector with respect to the base case.

- Using NG for industrial/transport/ household and commercial sectors have to be promoted through suitable policy decisions made by relevant authorities.

\section{Electricity for the Transport Sector}

The use electricity in the transport sector was tested using a specified plan. The model suggests that the given plan is economically viable. The introduction of electric vehicles to the public transport system (including railways) should be taken into consideration by policy makers and the required incentives given to increase the number of electric vehicles. Even in the sensitivity analysis, the plan for using electricity in the transport sector remains as an economically viable solution.

- Policies should be prepared targeting the accelerated introduction of electric vehicles by giving proper incentives to the people.

5. Meeting the Urea Demand

The model output proposes that manufacturing urea within the country is more economical than importing it. Furthermore in the sensitivity analysis, except in the "Sensitivity Analysis - High LNG and NG Price Case", the model suggests as the best option the meeting of the urea demand completely through urea plants. (The total number of urea plants is 3 , throughout the planning period, each with 0.5 MT/year production capacities). However, in the "High NG/LNG price case", the model proposes to have only two urea plants for the planning period and to meet the remaining urea demand through direct urea imports.

- Decisions and policy directives need to be taken to build up urea plants to meet the urea demand of the country.

6. Non - viability of the Existing Refinery The model, in its optimized output, suggests that it is more economical to import refined nroducts than using the nroducts from the existing refinery. However, the shutting down of the refinery will cause many other social and economic issues. Also, it can affect the energy security of the country. Therefore, it is suggested to study the options available to operate the existing refinery at least at breakeven level

\section{General}

The results of this study are highly dependent upon government policy. Also due to the limitations of the model given in Section 6 "Limitations of the Model", the results were not deterministic but highly probabilistic.

The government is likely to abandon the erection of new coal power plants and this case has been analysed under Item No. 9 of the Sensitivity Analysis. Furthermore, if the SOREM project is not going to commence, the results of this study will have to be amended accordingly.

Figure 16 shows the anticipated proportions of energy supply in the long run by the fuel/source.

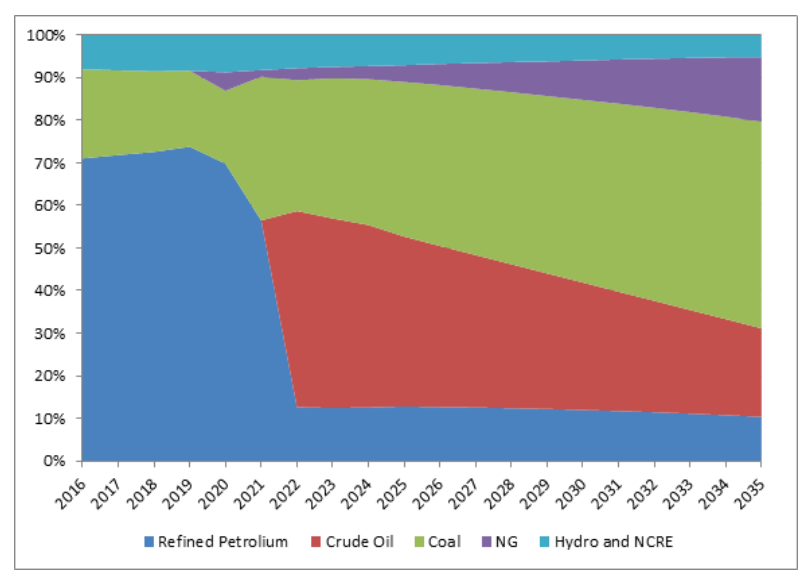

Figure 16 - Anticipated proportions of energy supply in the long run by the fuel/source.

In addition to the conclusions, it is recommended to prepare a Least Cost LongTerm Energy Supply Strategy for Sri Lanka, for the Usage of Petroleum, Coal and Natural Gas on a rolling basis with a frequency that is less than that of LTGEP (e.g.: Once in every 4 years). A model like this should be used in the planning stages of the government's energy policy, introducing a new technology, new energy source or any other major change to the energy sector. 


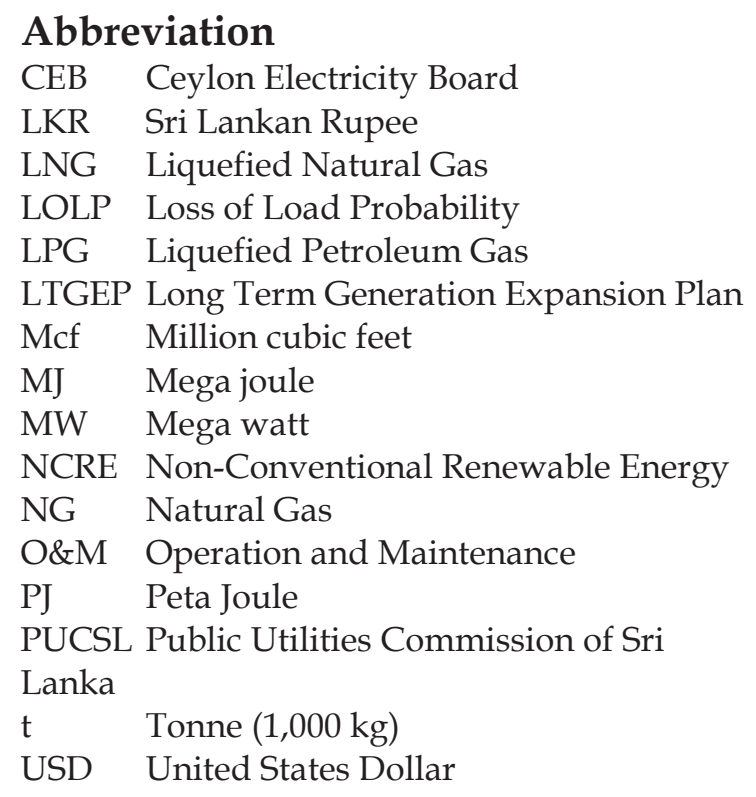

\section{Acknowledgement}

Authors wish to express their thanks to the Department of Electrical Engineering, University of Moratuwa, Public Utilities Commission Sri Lanka, Ceylon Petroleum Corporation and Ceylon Electricity Board for the support extended during this study.

\section{References}

1. Ceylon Electricity Board, Long Term Generation Expansion Plan 2015 - 2034.

2. Ceylon Electricity Board, Long Term Generation Expansion Plan 2013 - 2032.

3. International Atomic Energy Agency, MESSAGE, Model for Energy Supply Strategy Alternatives and their General Environmental Impacts (User Manual), 2007.

4. Petroleum Resources Development Secretariat, Sri Lanka, Natural Gas - New Energy Resource in Sri Lanka (Phase 1 - Initial natural gas utilization road map), 2014.

5. Fairuz, S. M. C., Sulaiman, M.Y., Lim, C. H., Mat, S., Ali, B., Saadatian, O., Ruslan, M. H., Salleh, E. \& Sopian, K., “'Long Term Strategy for Electricity Generation in Peninsular MalaysiaAnalysis of Cost and Carbon Footprint using MESSAGE", Energy policy, Vol. 62, 2013,pp.493502.

6. Klaassen, G., \& Riahi, K., “Internalizing Externalities of Electricity Generation: An Analysis with MESSAGE-MACRO", Energy Policy, Vol. 35, No.2, 2007, pp. 815-827.

7. Hainoun, A., Aldin, M. S., \& Almoustafa, S., "Formulating an Optimal Long-Term Energy supply strategy for Syria using MESSAGE model", Energy policy, Vol. 38, No. 4, 2010, pp.1701-1714

8. Norvaiša, E., \& Galinis, A., “Future of Lithuanian Energy System: Electricity Import or Local Generation?", Energy Strategy Reviews, Vol 10, 2016, 29-39.

9. Després, J., Hadjsaid, N., Criqui, P. \& Noirot, I., "Modelling the Impacts of Variable Renewable Sources on the Power Sector: Reconsidering the Typology of Energy Modelling Tools", Energy, Vol. 80, 2015, pp.486-495.

10. Eberhard, M. \& Tarpenning, M., The 21st Century Electric Car, Tesla Motors Inc., 2006.

11. Haugneland, P, "Norwegian Electric Car user Experiences 2014", European Electric Vehicle Congress Brussels, Belgium, $3^{\text {rd }}-5^{\text {th }}$ December 2014.

12. Hainoun, A., Aldin, M. S., \& Almoustafa, S., "Formulating an Optimal Long-Term Energy Supply Strategy for Syria using MESSAGE Model", Energy policy, Vol. 38, No. 4, 2010, pp.1701-1714.

13. Sustainable Energy Authority of Sri Lanka, Sri Lanka Energy Balance - 2014, Sri Lanka, 2015.

14. Sustainable Energy Authority of Sri Lanka, Sri Lanka Energy Balance - 2013, Sri Lanka, 2014.

15. Sustainable Energy Authority of Sri Lanka, Sri Lanka Energy Balance - 2012, Sri Lanka, 2013. 